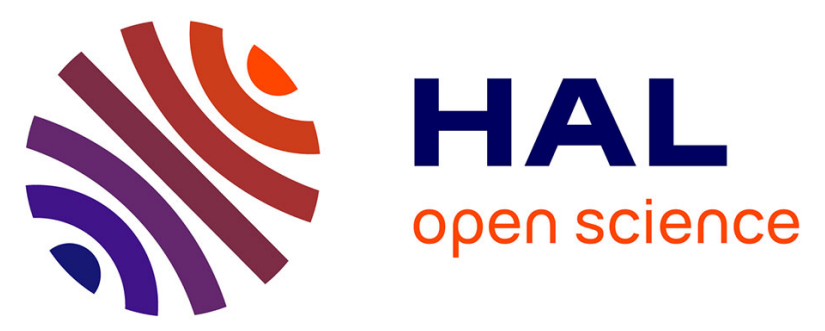

\title{
One Health concepts and challenges for surveillance, forecasting and mitigation of plant disease beyond the traditional scope of crop production
}

Cindy E. Morris, Ghislain Geniaux, Claire Nédellec, Nicolas Sauvion, Samuel Soubeyrand

\section{To cite this version:}

Cindy E. Morris, Ghislain Geniaux, Claire Nédellec, Nicolas Sauvion, Samuel Soubeyrand. One Health concepts and challenges for surveillance, forecasting and mitigation of plant disease beyond the traditional scope of crop production. Plant Pathology, 2022, 71, pp.86-97. 10.1111/ppa.13446 . hal-03154445

\section{HAL Id: hal-03154445 \\ https://hal.inrae.fr/hal-03154445}

Submitted on 28 Feb 2021

HAL is a multi-disciplinary open access archive for the deposit and dissemination of scientific research documents, whether they are published or not. The documents may come from teaching and research institutions in France or abroad, or from public or private research centers.
L'archive ouverte pluridisciplinaire HAL, est destinée au dépôt et à la diffusion de documents scientifiques de niveau recherche, publiés ou non, émanant des établissements d'enseignement et de recherche français ou étrangers, des laboratoires publics ou privés.

\section{(1) (1) $\$$}

Distributed under a Creative Commons Attribution - NonCommercial - NoDerivatives| 4.0 


\title{
One Health concepts and challenges for surveillance, forecasting and mitigation of plant disease beyond the traditional scope of crop production
}

\author{
C.E. Morris ${ }^{1}$, G. Géniaux ${ }^{2}$, C. Nédellec ${ }^{3}$, N. Sauvion ${ }^{4}$, S. Soubeyrand ${ }^{5}$ \\ 1INRAE, Pathologie Végétale, F-84140, Montfavet, France, cindy.morris@inrae.fr \\ 2INRAE, Ecodéveloppement, F-84914, Avignon, France \\ 3Université Paris-Saclay, INRAE, Mathématiques et Informatique Appliquées du Génome à \\ I'Environnement, F-78352 Jouy-en-Josas, France \\ ${ }^{4}$ PHIM Plant Health Institute, Univ. Montpellier, INRAE, CIRAD, Institut Agro, IRD, Montpellier, France \\ 5INRAE, BioSP, F-84914, Avignon, France
}

\section{Abstract}

Manuscript submitted to Plant Pathology on 27 Feb 2021

The One Health approach to understanding disease epidemiology and achieving surveillance and prevention is holistic all while focusing on zoonotic diseases. Many of its principles are similar to those espoused in Agroecology, begetting the question of what One Health can contribute - in practice - to preventing plant disease. Here we describe four knowledge challenges for plant health management that have arisen from the One Health experience for zoonotic diseases that could boost prospects for novel approaches to plant disease surveillance, prediction and prevention. The challenges are to i) uncover reservoirs and revise pathogen life histories, ii) elucidate drivers of virulence beyond the context of direct host-pathogen interactions, iii) account for the natural highways of long distance dissemination (i.e., surface water and air mass movement), and iv) update disease forecasts in the face of changing land use, cultivation practices and climate. Furthermore, we note that implementation of a One Health approach to disease surveillance and prevention will require mobilization of tools to deal with the representation and accessibility of massive and heterogeneous data and knowledge; with knowledge inference, data science, modelling, and pattern recognition; and multi-actor approaches that unite different sectors of society as well as different scientific disciplines. The infrastructure to build and the obstacles to overcome for a bona fide One Health approach to disease surveillance and prevention are the key commonalities where actors in the efforts to prevent zoonotic diseases and plant disease can work together for human, animal and plant health and sustainable management of biodiversity.

\section{INTRODUCTION}

The conceptual framework for emergence and dynamics of disease of humans and animals was shaken to its core by a series of novel diseases starting in the 1970's. This began with HIV and continued with Legionnaire's disease, SARS, cryptococcal meningoencephalitis, and others up to the current Covid-19 pandemic. One of the common features of these disease emergences was that they all involved spillover ${ }^{1}$ (Tab. 1) of microorganisms from natural habitats into human habitats that was favored by the growing proximity of human activities to natural or wild environments. The emergence of these diseases was exacerbated by increasing human

\footnotetext{
${ }^{1}$ Table 1 presents definitions of some of the terms used in this text that might not be well known by readers of Plant Pathology.
}

travel and globalized trade. The scenarios to explain these emergences drew attention to the range of processes that connected otherwise disparate environments and, in particular, the increasing connectivity (Tab. 1) of natural habitats with human habitats. These novel diseases - that now account for about $75 \%$ of all new infectious diseases of humans (Center for Disease Control, 2017) - also brought to the forefront questions about how virulence to humans can arise in microorganisms that have not been in contact with humans prior to their emergence as human pathogens. Research into these questions has revealed dual-use traits (Tab. 1) that simultaneously (and serendipitously) allow microorganisms to survive biotic and abiotic stresses 
in their natural habitats and to contribute to virulence when the microorganisms encounter humans. Predation, desiccation, ultraviolet radiation and the activity of the immune system of nonhuman/primate mammals are examples of the types of environmental stress that provide positive selection pressure on microorganisms for traits that can facilitate virulence to humans (Casadevall \& Pirofski, 2007; Erken et al., 2013; Ye et al., 2020).

This new insight on disease emergence has illustrated that epidemics involve phenomena well beyond the system or habitat where disease epidemics occur. It has pointed out the need for highly interdisciplinary research approaches to identify indicators and key drivers of epidemics that account for biological and evolutionary phenomena in these other habitats and the connectivity of all habitats involved in disease emergence. It has also altered the targeted scope of surveillance for human diseases and has given rise to initiatives to include surveillance of wildlife reservoirs, for example. And finally, it highlights how the fast pace of climate change and global change - deforestation in particular(Austin, 2021) - in this modern epoch of the Anthropocene (Steffen et al., 2016) continuously alters the ambient conditions that influence microbial growth and survival, the connectivity between human and wild habitats and the intensifying connectivity of habitats occupied by humans.

This new perspective on the epidemiology and management of human diseases has been termed "One Health". The One World One Health perspective took shape at a meeting on wildlife conservation in 2004 (Hinchliffe, 2015). It was inspired by common sense about zoonotic diseases and it promotes the idea that human, animal and environmental health are systemically entangled. The One Health initiative was intended to unite human and veterinary medicine, social sciences, conservation practices and policy making more coherently by providing a common analytical framework to avoid zoonotic outbreaks and spread. One Health can be distinguished from the similar EcoHealth approach in that the former focuses more on the importance of the animal-human link in disease emergences than does the latter (Harrison et al., 2019). However, both approaches are highly anthropocentric and consider the state or health of other organisms as a means to attain the goal of human health. The dynamics, scope and ambition of the global effort to deploy the One Health perspective to mitigate the emergence of zoonotic diseases is embodied in initiatives such as the EcoHealth Alliance (https://www.ecohealthalliance.org/). This alliance funds and coordinates international programs on prediction and prevention of zoonotic disease epidemics, covering subjects from identifying hot spots for disease emergence, establishing biosurveillance networks, bioeconomic modelling to balance conservation with industrial use of forests, assuring that science informs policy-making about conservation and development, and educating scientists and stakeholders about One Health.

Overall, the One Health and EcoHealth concepts provide a holistic and comprehensive framework in which to explore the factors that are key to the emergence of human diseases and that can be leveraged for prevention. For both concepts, plants are accounted for as part of the environmental component of systems. Plants are a component that will be exposed to the alterations - often of anthropogenic origin - endured by the habitats they occupy. They are also a component that constitutes food sources essential to the health of humans and animals. Some authors have also proposed that plants are a bridge between the environment, humans and animals via which microorganisms can circulate (van Bruggen et al., 2019). However, in practical terms, what can the One Health concept contribute to understanding and managing plant disease? It could be argued that One Health promotes a comprehensive perspective that has already been fostered for decades by the principles of Integrated Pest Management and more recently in the growing field of Agroecology (Tab. 1) and implicitly in the Millennium Sustainable Development goals (Lechenet et al., 2017). For example, the role of spillover of plant pathogens from reservoirs outside of cultivated areas has been recognized in the epidemiology of some plant diseases (Power \& Mitchell, 2004). Eradication of reservoirs outside of cropped areas or in stands of weeds was deployed from the early to mid-1900's to 
manage stem rust of wheat by eradicating the alternate host - barberry (Peterson, 2018). It was also deployed to manage white pine blister rust by eradicating the alternate hosts - currants and gooseberries (Zeglen et al., 2010), and more recently to reduce the inoculum pressure of the numerous wild and ornamental hosts of the fire blight pathogen Erwinia amylovora (Sletten et al., 2017). Insect vectors of plant diseases, and especially piercingsucking sap-feeders, also illustrate the potential for spillover from wild to cultivated habitats. For example, the bacterium causing Olive Decline, Xylella fastidiosa - sensationalized in 2015-2016 after its discovery in Italy (Stokstad, 2015; Abbot, 2016) - was spread locally in orchards by Philaenus spumarius, the cuckoo-spit insect, very common in grasslands (Sicard et al., 2018). For the phytoplasma causing European stone fruit yellows, psyllid vectors caused complex spread patterns at multiple scales between cultivated and wild Prunus (Marie-Jeanne et al., 2020). Although considerable progress is needed to set pathogen ecology, evolution and life cycles in a broad context that can be leveraged to anticipate and mitigate eventual spillover (Morris et al., 2009; Malembic-Maher et al., 2020), the framework of Agroecology is touted as useful and pertinent for this effort(Burdon \& Thrall, 2008). Therefore, we wonder if One Health offers anything new for plant health.

Here we bring attention to four notable knowledge challenges for plant health management from the One Health experience for zoonotic diseases that could boost prospects for novel approaches to plant disease surveillance, prediction and prevention. We also describe how the impediments to implementing a One Health-like approach for surveillance and mitigation of plant disease are fundamentally the same as those for implementing One Health surveillance and mitigation for diseases of humans and animals. Many of the knowledge challenges and impediments are interdisciplinary. Therefore, we have provided definitions and description of some of the terms and tools in Tables 1 and 2. We also present, in Fig. 1, a synthetic view of the knowledge challenges and tools that need to be bridged to achieve surveillance and prevention of plant disease compatible with the goals of One Health for zoonotic diseases, as described in detail in the text below.

\section{KNOWLEDGE CHALLENGES FOR PLANT HEALTH MANAGEMENT FROM THE ONE HEALTH PERSPECTIVE}

\section{Uncover reservoirs and revise pathogen life}

histories. Many microorganisms that are capable of causing plant disease do not have obligate dependence on plant hosts and can exist as saprophytes or commensals. Likewise, insect-borne pathogens can be widely dispersed and spend considerable time away from crop hosts while in association with the insect vector (e.g., Thébaud et al., 2009). Therefore, it is likely that numerous plant pathogens persist in a wider range of habitats and have life histories that are more complex than currently accounted for in epidemiology (e.g., Cruaud et al., 2018; Soubeyrand et al., 2018). The rusts, fire blight, insect vectors and other diseases cited above that spillover from various reservoirs are examples of the possible extent of pathogen reservoirs and habitats. Comprehensive studies of habitats of additional pathogens, viz. Pseudomonas syringae and Botrytis cinerea, have shown that genetically similar populations with similar levels of pathogenic potential are present both in and outside of agricultural contexts and in association with substrates in addition to plant hosts (Morris et al., 2010; Monteil et al., 2016; Bardin et al., 2018). Many other bacteria, fungi and viruses have the requisite biological traits and have been observed to persist in the environment suggesting that it is reasonable to expect that they have life stages that do not require association with the hosts on which they cause disease (Morris et al., 2009). Insect vectors of plant pathogens can spend up to 9 months per year on a wide range of shelter plants (e.g., conifers) that are not the plants on which insects reproduce or develop, as in the case of psyllids (Cooper et al., 2019). Whereas the association of some plant pathogens such as Liberbacter spp. is limited to a few insect species, Xylella fastidiosa and some phytoplasmas have the capacity to associate with a seemingly unrestricted range of sap-feeding insects (Huang et al., 2020) thereby making for an extraordinary number of potential reservoirs.

An important challenge for the epidemiology of plant diseases is to explore the frontiers of the habitats of plant pathogens and to revise the portraits of 
pathogen life cycles and life histories accordingly. This does not necessarily mean that the number and scope of field observations need to increase dramatically. Discovery of unsuspected reservoirs of pathogens or insect vectors - and unsuspected vectors - could benefit from recent progress in text mining. For example, the Omnicrobe knowledge base and on-line service (http://migale.jouy.inra.fr/Florilege/) parses multiple textual sources including millions of PubMed references to extract mentions of microorganisms, geographical places, biotopes and phenotypes and their relationships and maps it to the Ontobiotope classification of habitats (Nedellec et al., 2018). It currently contains more than 45000 entries linking microbes and habitats that are plants or plant parts among which there are1180 plant pathogens and 7000 entries linking microorganisms and insects (Chaix et al., 2019).

Once new reservoirs are identified, the epidemiological risk posed by microorganisms in these reservoirs will also need to be estimated. This risk is composed of two components: the pathogenic potential of microorganisms in these reservoirs and the potential for spillover from reservoirs to crops. Up to present, efforts to estimate the phytopathogenic potential of microorganisms have focused on the breadth of host range and the phylogenetic affiliation (Bartoli et al., 2015; Morris et al., 2019) - the same indicators that have been identified as the most important for assessing risk of zoonotic potential in viruses (Olival et al., 2017). Assessing the actual spillover of pathogens from reservoirs to crops is a challenge at the intersection of spatial statistics, population dynamics, genetics and phylogeography (Mollentze et al., 2014; Picard et al., 2017; Rakotomalala et al., 2019; Malembic-Maher et al., 2020; Marie-Jeanne et al., 2020). The goal is to quantify the risk of spillover and, subsequently, to foster quantitative risk-based surveillance strategies designed for i) monitoring microbial populations that may include potentially emergent pathogens and ii) anticipating the heightened need to survey for pathogens after spillover. Such strategies should be stratified in space and time to account for habitat diversity, seasonal spillovers, ecological networks, microbe dynamics and anthropogenic activities.

\section{Elucidate drivers of virulence beyond the context} of direct host-pathogen interactions. As described above, some virulence factors also have roles in adaptation of plant pathogens to environmental stress and are under positive selection in absence of plant hosts as well as during disease causation. The dual use of virulence factors (Tab. 1) is a well-known phenomenon for numerous pathogens of animals and humans and its relevance to plant pathogens has been described previously (Morris et al., 2009). Some of the likely dual-use virulence factors for plant pathogens involve molecules such as melanin, exopolysaccharides, various non-specific toxins (e.g., lipopeptides), proteinases, etc. Positive selection for dual-use virulence factors can occur during interactions with a range of competitors and aggressors both in and beyond habitats associated with crop hosts. Predation experiments with $P$. syringae and invertebrates revealed a range of traits that fostered survival of $P$. syringae after predation (Dorati et al., 2018). These traits included production of alginate and other exopolysaccharides that have been shown to be involved in fitness or virulence of P. syringae when associated with plants (Markel et al., 2016; Helmann et al., 2020). Furthermore, the Type 3 Secretion System and its effectors facilitate the interaction of Gram-negative bacteria with a range of eukaryotes in addition to plants (Egan et al., 2014). This suggests that interactions with other eukaryotes could explain, at least in part, why strains of $P$. syringae collected in aquatic habitats outside of agriculture maintain a diversified repertoire of effector alleles in their genomes (Monteil et al., 2013, 2016).

The selection pressures described above operate on the foundation of the genetic diversity that arises in microbial populations. Habitats differ in their microbial diversity and in the environmental conditions that could in turn influence rates of genetic diversification. This could occur i) via mutation when there are compounds or conditions that enhance mutagenesis or activity of transposable elements and/or ii) via frequent opportunities for horizontal transfer of novel genetic material from the community of cohabitants (Olszak et al., 2017; Poursat et al., 2019). Together, diversification and selection are part of the process of adaptation that is 
highly context-dependent (Goh et al., 2013). Modelling reveals that the biotic context (species diversity, composition and mixing) is critical to the dynamics and outcome of adaptation. Therefore, prediction of the evolution of pathogens needs to account for the range of situations in which microorganisms evolve across space and time (Gorter et al., 2020)

There are important implications of dual-use traits for surveillance and management of plant diseases. Firstly, information about positive selective forces can guide surveillance toward reservoirs where these selective forces could be operating strongly for certain pathogens. Habitats with high rates of predation of bacteria and fungi by invertebrates could be singled-out in light of the significant influence of temperature and the nature of the habitat matrix on predation (Zahn et al., 2016). Habitat changes that lead to acidification and homogenization of the soil due forest management that favors conifers could also alter and reinforce selection pressures (Purahong et al., 2014). In addition, knowledge of habitats that favor hybridization and sexual recombination for example could orient surveillance and mitigation efforts as exemplified in the case of Cryptococcus spp. that are causing new emergences of cryptococcal meningoencephalitis. These fungi can reside in plant deadwood - in Eucalyptus spp. in particular - where their use of inositol enhances the rate of genetic variation of these fungi leading to variants that are virulent to humans and other animals (Xue, 2012). This has led to pertinent recommendations for the handling and monitoring of deadwood. Finally, knowledge about positive selection of dual-use virulence traits could be used to orient prophylaxis away from practices that would reinforce positive selection.

Account for the natural highways of long distance dissemination. Long distance dissemination of plant pathogens and insect vectors can occur via natural processes that are operating constantly such as surface water flow and air mass circulation. Examples of such long distance dissemination are illustrated by the intercontinental spread of various rust fungi (Brown \& Hovmøller, 2002; Meyer et al., 2017), the spread of aphid-borne viruses at the landscape scale (Pleydell et al., 2018), the spread of powdery mildew throughout an archipelago (Soubeyrand et al., 2009), and the spread of Phytophthora ramorum via waterways (Hohl et al., 2014). When natural dissemination is feared to be critical to the invasion of a new region by a devastating pathogen, sufficient observatories and international collaborations can be set up to predict the time and place of this invasion. This was achieved for the arrival of soybean rust in the continental USA (Isard et al., 2005). However, the significance of natural long distance dissemination processes for most plant pathogens and their vectors - compared to long distance spread by trade and commerce - has not been assessed. The major obstacle to knowing the extent and frequency of natural long distance dissemination is the quasi infeasibility of directly observing such events and therefore the lack of data. Attempts to collect such data would be less futile if there were strong hypotheses about likely trajectories of dissemination and their dynamics.

One recent approach to evaluating the significance and predictability of naturally occurring long distance dissemination for disease outbreaks is to characterize the probable dissemination routes themselves. The logic underlying this approach is that once pathogen propagules or insect vectors are entrained by air masses or water flow, they will travel passively until they are released (scrubbing, deposition, etc.) or die. Whereas most surface water flow (rivers, etc.) has been mapped, aerial "highways" have not been mapped. In a recent study, mathematical formalism was used to estimate, from archived meteorological data, spatiotemporal networks generated by trajectories of air masses across watersheds in southeastern France and across the coastline of the Mediterranean Sea (Choufany et al., 2021a). The marked seasonal patterns of air mass movements detected across the Mediterranean Sea in particular illustrate how air sampling could take into account seasonal variations to orient efforts toward the most opportune sites and conditions for detection depending on suspected pathogen sources (Choufany et al., 2021b). The networks revealed in this work could also be the basis for modifications in 
modelling disease spread to account for realistic trajectories of dissemination. Overlaying these trajectories on land use could reveal risky "flight zones".

To identify the probable long distance dissemination trajectories via water and air, it will be necessary to have access to and the capacity to manage large volumes of data. For example, the networks of air mass movement revealed by Choufany and coworkers involved the estimation of $>3.6$ million trajectories with the Hybrid Single-Particle Lagrangian Integrated Trajectory model available from the NOAA Air Resources Laboratory platform (https://www.ready.noaa.gov/HYSPLIT.php) and their analysis. Being able to carry out cross-analyses (using machine learning or mechanistic models) of such massive data is a major challenge for building pertinent knowledge in a One Health approach of plant health. It will be a means to revealing the potential habitat connectivity and to coupling it to data about the pathogen, land use and other environmental variables. This will give credibility to scenarios of long distance dissemination and will orient surveillance and disease management actions accordingly. Given the extent of the possible connections when using such high dimensional data, the use of co-modelling approaches and the recently developing field of interpretable machine learning, coupled to suitable panels of scientific experts, will become increasingly useful (Che et al., 2015; Ghosal et al., 2017; Du et al., 2019). This emerging analytical approach will ensure the robustness of the relationships identified by enhancing the capacity to detect and remove bias and to provide sound explanations of predictions in the interdisciplinary context that is advocated by the One Health approach.

\section{Update disease forecasts in the face of changing land use, cultivation practices and climate. Crops} and their associated cultivation practices such as irrigation are spatially organized in a context of other vegetation, soil types, rainfall frequencies, urbanization, etc. In interaction with climate, these spatialized factors influence all stages of the epidemic risk: the location of hosts, their connectivity to each other and to natural or cultivated areas, their genetic diversity, dissemination networks linked to irrigation, and pest management. The role played by the current spatial organization of land use in plant health is still poorly understood. The rapid change of spatial relationships due to changing climate (that alters rainfall patterns or the extent of biotopes, for example) and to globalization of trade will be exacerbated as pressures on land use increase. In this context, changing climate regimes will force disease emergences and epidemics into circumstances not accounted for in current epidemiological models. This has been pointed out in particular for vectortransmitted disease where these changes affect not only host plant receptivity but also vector life cycle and competence (Daugherty et al., 2017; Godefroid et al., 2018). Without sufficient foresight, these deviations will hamper the effectiveness of current surveillance strategies for managing plant health.

To move plant disease epidemiology and surveillance toward a One Health-like approach, we need a framework to better anticipate epidemics in a changing environment that will foster the leveraging of biological, agronomic and socio-economic phenomena to prevent disease. Comparing and forecasting epidemics in different regions with dataoriented approaches that implicitly account for spatially heterogeneous factors (Soubeyrand et al., $2020 \mathrm{~b}$ ) is a first step toward assessing preparedness and vulnerability to disease emergence and outbreak (Ribaud et al., 2021). From a more mechanistic perspective, estimating spatial patterns of the risk of spillover from reservoirs within and outside of cultivated regions could be a second benchmark goal. Models could then be developed to minimize risk - locally and globally - as a function of demographic, economic, social and cultural constraints that are heterogeneous over space and time. Whatever their goal, models should be focused on a sound identification of the possible drivers of plant disease in a data-rich context and on evaluating the pertinence of these drivers. Pertinence could be evaluated in terms of facilitating early detection, reducing the costs of observation/detection, reducing the uncertainty of the risk assessment, providing avenues for disease prevention or control, and being comprehensible and actionable by 
stakeholders in different sectors of activity. Ideally, these models would incorporate forecasts for trends in cultivation practices such as pesticide use and irrigation, climate, and agricultural markets and could plug into existing simulations of land use change (Holman et al., 2017). Indeed, such a framework would resemble the essence of the One Health approach. In particular, it sets the goal of surveying for indicators from a wider spectrum of time, space and sectors of society than are currently implicated in plant disease surveillance. Furthermore, this framework would integrate factors related to stakeholder behavior thereby yielding forecasts that might be more amenable to realistic mitigation strategies.

\section{DISCUSSION - TWO HEALTHS WORKING AS ONE}

Efforts to control plant diseases and those to control human and animal diseases have very little overlap in terms of the causal agents they target. Furthermore, management of plant health concerns tens of thousands of species of crop, forest and ornamental plants (Khoshbakht \& Hammer, 2008), many of which are further subdivided into botanical varieties, cultivars and landraces that have distinctive niches and utility as sources of food, feed, fiber and as the foundation of livelihoods (de Carvalho et al., 2016). Nevertheless, the epidemiology and management of diseases of plants, humans and animals share a multitude of conceptual frameworks and infrastructural requirements in addition to data needs, the partnerships to be established for effective surveillance, and the initiatives being taken for global coordination of disease management efforts. There are already bridges between medical and plant microbiology concerning concepts of pathogen ecology and evolution that will take on increasing importance for building One Health-like approaches for plant health. In contrast, collaborations and infrastructure to build One Health surveillance systems for plant, human and animal health are lacking and need to be fostered.

Whereas there is no consensus on the definition of epidemiological surveillance based on the One Health approach (OH-ES), such a system is expected to collect data in multiple fields and to foster inter- sectoral and inter-disciplinary collaborations (Destoumieux-Garzón et al., 2018; Bordier et al., 2019 , 2020). In other words, to achieve OH-ES will require consolidating data that are currently partitioned between human health, animal health, food production and safety, and ecosystem health. Therefore, a common challenge for all One Healthlike disease surveillance and management initiatives will be building open, interoperable, and regularly updated catalogs of data from heterogeneous sources. The detection and interpretation of unstructured information available on the internet (Barboza et al., 2013), its combination with official information and published scientific knowledge in a unified framework raise challenges at the interface of text and data mining, data-linking and knowledge representation (Collier, 2012). These issues are wellidentified in biology (Bossy et al., 2015) and in agriculture (Dzale Yeumo et al., 2017). However, the limited access to relevant textual data, the lack of standards for text structure and for information description, and the high diversity of data sources intensify the challenge for epidemiological surveillance. However, the standardization of information in agriculture through the development of ontologies (Tab. 1) (Jonquet et al., 2018) and the recent advances of deep learning methods (e.g. word embedding) have dramatically improved information extraction by Natural Language Processing (Tab. 1). This now makes it realistic to formalize and classify information (e.g. niche, vector, phenotype, disease descriptions) in thousands of classes with little or even no training.

Large-spectrum open data will be the bedrock of enhanced surveillance, forecasting and prophylaxis. Its ideal scope would be beyond the frontiers of cropped fields and greenhouses and beyond the closed-system vision of many of the current expert knowledge-based models of pathogen dynamics. The spectrum of data would span from variables directly related to pathosystems, to data related to explanatory variables that are classically used for pathosystems, to variables that are unexpected and perhaps indirectly related but that can be used to build efficient epidemiological indicators for nowcasting and forecasting disease emergence and dynamics. Whereas the last decade has resulted in an 
impressive availability of indirect data in multiple fields of science (geography, meteorology, climatology, economy - see https://www.copernicus.eu, https://www.dataterra.org, https://data.europa.eu), the race to maintain competitive economic or scientific advantages has prompted reluctance to share some data. There is also fierce opposition from the agricultural sector to make available data on pesticide use, for example. Although data at increasingly finer scales are becoming available through advances in remote sensing and advances in the availability of administrative data (e.g. https://www.data.gouv.frlen/datasets/registre-parcellairegraphique-rpg-contours-des-parcelles-et-ilots-culturaux-et-leurgroupe-de-cultures-majoritairel), there are still technical issues about the nature of the data. These include limitations in the spatial resolution of data about individual farm practices, gaps in information about plant species (especially in the wild), insect vectors and biodiversity in general, as well as transportation of plant materials, natural dissemination routes, and links in ecological networks. Some of these gaps could be reduced by exploiting data generated by citizen science (Botella et al., 2018) and crowdsourcing of field scouts' information used in direct epidemiological surveillance, by building knowledge or mapping information mined in documents containing texts (Przybyła et al., 2016), by reconstructing information from remote sensing (lenco et al., 2019) and by inferring source-sink connectivity via air mass movements (Choufany et al., 2021a). Narrowing the gaps will also be driven by continued incentive (from government agencies, research institutes and funding agencies) for FAIR data principles (Findability, Accessibility, Interoperability, Reusability; Wilkinson et al., 2016). The shift toward the use of large-spectrum data in a One Health vision of plant health may be facilitated by dedicated teaching, capacity building and data catalog web portals (such as the European Open Science Cloud https://eosc-portal.eu) adapted to surveillance, forecasting and prophylaxis in the context of plant epidemiology. As a feedback, such initiatives could increase the attractiveness of research and teaching professions in plant health.
Not only are there technical and legal issues to surmount in order to unite these diverse data, there will be social and cultural hurdles. Inter-sectorial and interdisciplinary collaborations are frequently difficult to bring to fruition for various reason stemming from the inertia of institutions (barriers to information exchange between institutions, fear of loss of leadership, difficulty in allocating financial resources adequately) and the lack of incentives for multidisciplinary collaboration in academic research (teaching; lack of renowned inter-disciplinary scientific journals, scientific recognition, and research funding) (Häsler et al., 2014; Allen \& Mehler, 2019). Furthermore, not only specialists are concerned by One Health, but citizens as well should be provided with means to be informed (e.g., with user-friendly web interfaces; Soubeyrand et al., 2020a) or with glossaries providing simplified definitions like those in Table 1). They should also be involved (e.g., with participatory science initiatives; https://plantnet.org/en/) in the One Health framework, especially when plant health issues are of concern, to raise the awareness for Earth biodiversity and increase the capacities for epidemiological surveillance. Overcoming these formidable hurdles to transform disease surveillance and management into something that resembles the ideals of One Health will be greatly facilitated by indicators of the impact and benefits of interdisciplinary and intersectorial collaboration and data sharing. Currently, there is a scarcity of research on these issues. Furthermore, difficulties in measuring the costs and benefits of an $\mathrm{OH}-\mathrm{ES}$ is perceived as an additional obstacle to their development (Häsler et al., 2012, 2014; Rabinowitz et al 2013 ; Destoumieux-Garzón et al., 2018).

By joining the cause of One Health, Plant Pathology has much to learn from the considerable progress in the conceptual understanding of disease emergence and epidemiology from recent paradigm shifts concerning zoonotic diseases that led to the One Health perspective. However, casting new research approaches in epidemiology and ecology under the label of One Health is only a small part of the effort needed to adopt practices inspired by One Health. Building bridges across the different sectors involved in plant health management and the tools and 
infrastructure for collective and coherent management of plant health (Fig. 1) is perhaps the most consequential challenge for modernizing plant health management. Facing this challenge provides an opportunity to reinforce interdisciplinary research and development in plant sciences and their attractiveness as domains for employment for future generations. Another important goal for plant health in the realm of One Health is for plant pathologists, agronomists and horticulturists to participate in intergovernmental initiatives to mitigate disease emergence through protection and management of Earth's biodiversity such as the Intergovernmental Science-Policy Platform on Biodiversity and Ecosystem Services (https://ipbes.net/about). Representatives of research institutes and organizations for managing crop health - in addition to those representing forestry - need to be at the table for initiatives to restructure agriculture to avoid emergence of human diseases (Duru \& Le Bras, 2020 ) in ways compatible with sustainable crop production.

\section{Acknowledgements}

The authors acknowledge the support of funding from the French National Research Agency (ANR) for the SPREE project (contract \# 17-CE32-0004) that supported the work of CEM, GG and SS and for the BEYOND project (contract \# 20-PCPA-0002) that supported the work of all authors.

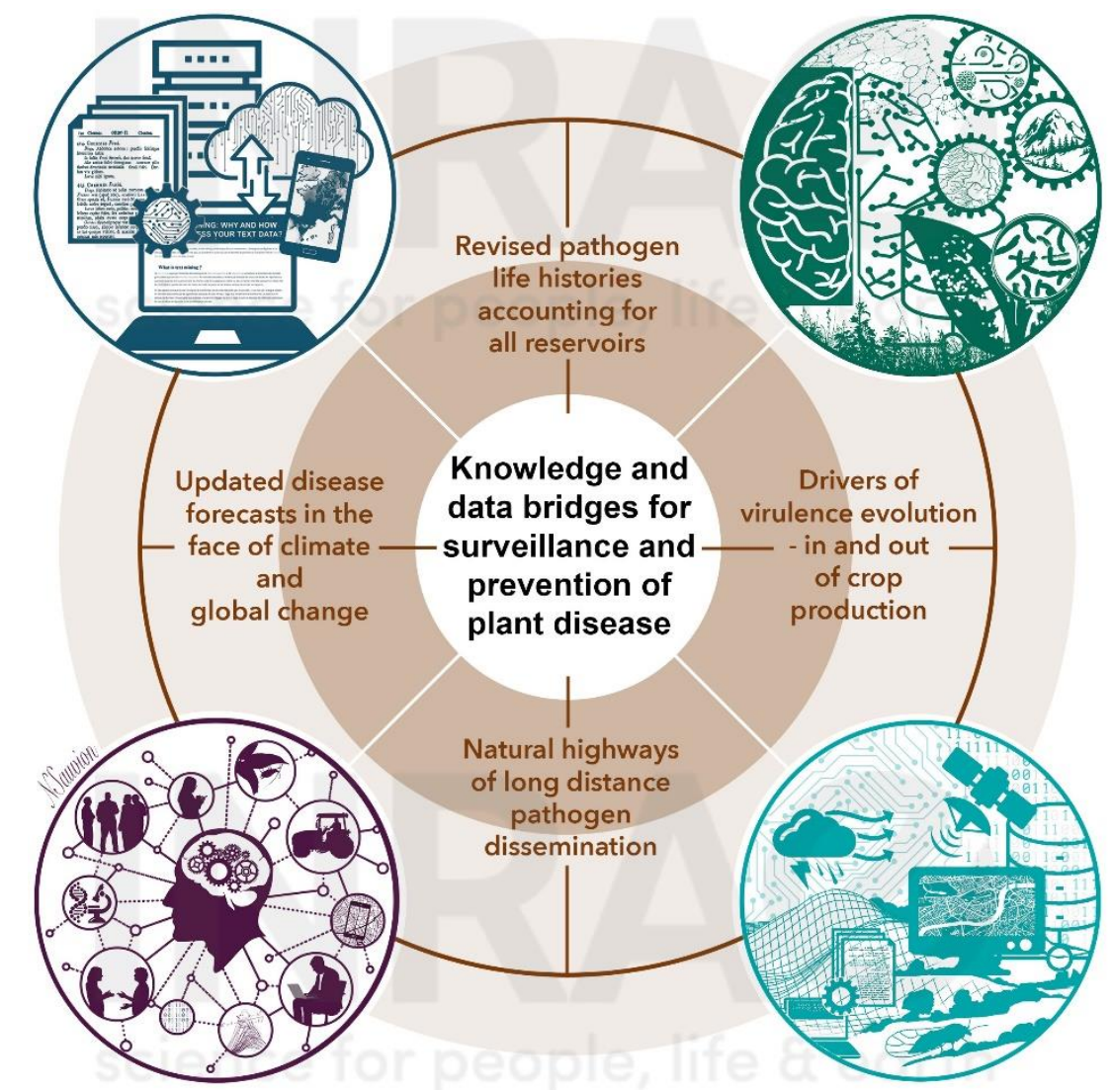

Figure 1. Challenges, methods and tools that need to be bridged via multidisciplinary approaches for enhancing surveillance and prevention of plant diseases from a One Health perspective. The knowledge challenges (brown text inside the circle) are described in the main text. The methods and tools (colored, round icons) to be mobilized to achieve surveillance and prevention of plant disease in the context of One Health deal with the representation and accessibility of data and knowledge (blue icon, upper left); knowledge inference, modelling, and pattern recognition (green icons, upper and lower right); and multi-actor approaches (purple icon, lower left) (see Table 2 for details about methods and tools). (NB: This version of the figure has a water mark.) 
Table 1. Definition of terms used in this paper

Term Definition

As a scientific discipline, Agroecology is the study of the ecology of an entire food system from Agroecology an approach that integrates biological, social and economic dimensions. Inversely, it can also be considered as a science of designing and managing agricultural systems using ecological principles (Francis et al., 2003; Gliessman, 2007).

Connectivity

Connectivity is a measure of the link between distal entities or of the potentiality of this link. It can be quantified with, for example, a probability of contact or a measure of flux or exchange.

Dual-use virulence The concept of dual-use virulence factors was originally introduced to explain the observation factors that some virulence factors of environmentally acquired microbes also promoted microbial survival in the environment (Casadevall \& Pirofski, 2007)

Natural Language Processing (NLP) is a subdomain of artificial intelligence that aims at Natural language developing computer programs to automatically process and interpret natural language (i.e. processing human language) utterances in the form of speech or written text. Automatic translation, information extraction, information retrieval, summarization, and speech recognition all involve NLP methods.

Ontologies provide standard interconnected representations of data, information and knowledge. Ontologies are used in information systems to define the structure of the data in an expressive way through relationships, hierarchies, restrictions or rules, for example. Ontologies and the related data can be processed by machines in an unambiguous way due to their formal representation.

An example of ontology for microbe biotopes is the Ontobiotope ontology: it defines habitats Ontology and phenotypes of microorganisms as hierarchies of classes (e.g., the forest class is more general than the tropical forest class). The data of the Omnicrobe database concerning habitats and phenotypes of microorganisms are indexed using Ontobiotope such that the Omnicrobe database can be queried at different levels of generality (e.g., are there microbes living in seasonal dry tropical forest or tropical rain forests or tropical forests or forests and that are plant pathogens and acidophilic?) (Chaix et al., 2019).

Another well-known example is the Gene Ontology that is used to index genes by molecular functions, biological processes and cellular components (Ashburner et al., 2000).

Risk-based and stratified surveillance A surveillance is risk-based when the sampling intensity (in a location or time) depends on the local measure of the risk (e.g., risk of emergence, risk of presence, risk of outbreak...). It is stratified when the rules for computing the sampling intensity depend on the stratum (e.g., the habitat, the population, the region...).

Spillover is the transmission of a generalist pathogen from a reservoir host to different host.

Spillover Depending on the relative importance of the reservoir and primary hosts and on the chronology of the transmission, the phenomenon can be referred to as spill-over or spill-back (Daszak et al., 2000; Power \& Mitchell, 2004)

Text-mining is the process of analyzing textual data to extract information from heterogeneous document types, such as web pages, emails, social media posts, journal articles, etc. and

Text-mining mapping it to semantic structures. This is done by identifying patterns within texts, such as trends in words usage, syntactic structure, etc. It relies on Artificial Intelligence methods, mainly Machine Learning and Natural Language Processing. 
Table 2. Examples of methods and tools useful for developing knowledge and data bridges for surveillance and prevention of plant disease and, in particular, for addressing the four challenges outlined in the main text and in Figure 1.

\begin{tabular}{|c|c|}
\hline Family of techniques & Technique \& Description \\
\hline \multirow{6}{*}{$\begin{array}{l}\text { Data and knowledge } \\
\text { representation and } \\
\text { accessibility }\end{array}$} & Data integration by ontology \\
\hline & $\begin{array}{l}\text { The alignment of the data is a key point for reusing and processing observations } \\
\text { and analytical results from multiple sources. This is done by mapping the data } \\
\text { to standard shared representations or schema, e.g. classification of habitats, } \\
\text { vectors, phenotypes, nomenclature of geographical locations, and taxonomy of } \\
\text { species. It relies on semantic web technologies, ontology alignment, data } \\
\text { linking or fusion. }\end{array}$ \\
\hline & Data and service catalogs on web portals \\
\hline & $\begin{array}{l}\text { Catalogs of data and services available from web portals dedicated to } \\
\text { epidemiological surveillance for facilitating the integration of heterogeneous } \\
\text { data and cross-analyses. The data and services are made interoperable through } \\
\text { standard access and description. The underlying open, web- } \\
\text { based platformswould enable scientific workflow design and run, supporting } \\
\text { accessible, reproducible, and transparent computational research in } \\
\text { epidemiological surveillance. }\end{array}$ \\
\hline & Data and knowledge search and visualization \\
\hline & $\begin{array}{l}\text { The interpretation of huge sets of data for decision or formulation of new } \\
\text { hypotheses is a critical step of the experimental approach. It requires powerful } \\
\text { tools for browsing, searching, highlighting patterns in a easy-to-use way } \\
\text { according to the task and the user profiles (research from various fields, farming, } \\
\text { public policy). Data visualization and more generally human computer } \\
\text { interaction (HCl) provide such tools. }\end{array}$ \\
\hline
\end{tabular}

Knowledge
inference, modelling
and pattern
recognition

Ontology-based information extraction (OBIE)

The information that is automatically extracted from textual documents (entities, relations) can be reused and combined with information from other sources when it is formalized using standard representation (e.g. ontologies, nomenclature). This is called normalization or semantic annotation. The information extraction methods combine linguistic information (e.g. syntactic dependencies) and domain knowledge, such as known reservoirs for given species. OBIE is a very hot topic renewed by the recent advances in natural language processing (NLP).

Intelligent system design

Using hybrid approaches of machine learning, knowledge representation and reasoning for complex problem processing, constraint-aware learning, explanatory power, trust.

\section{Machine learning}

Machine learning permits carrying out such actions as i) supervised regression that can reveal the links between observed variables, or ii) unsupervised clustering to characterize different patterns of situations, for example. When applied to large volumes of data, recent deep learning methods identify patterns based on limited reference data. Heterogeneous spatio-temporal data such as satellite images, time-series and scientific article collections are examples of data that can be treated by such learning approaches.

\section{Mechanistic modelling}

Mechanistic modelling can be used for assessing, in space and time, the risk of spillover and can forecast emergences and outbreaks by taking into account life cycles of species under consideration (pathogens, hosts, vectors). 
Table 2. continued.

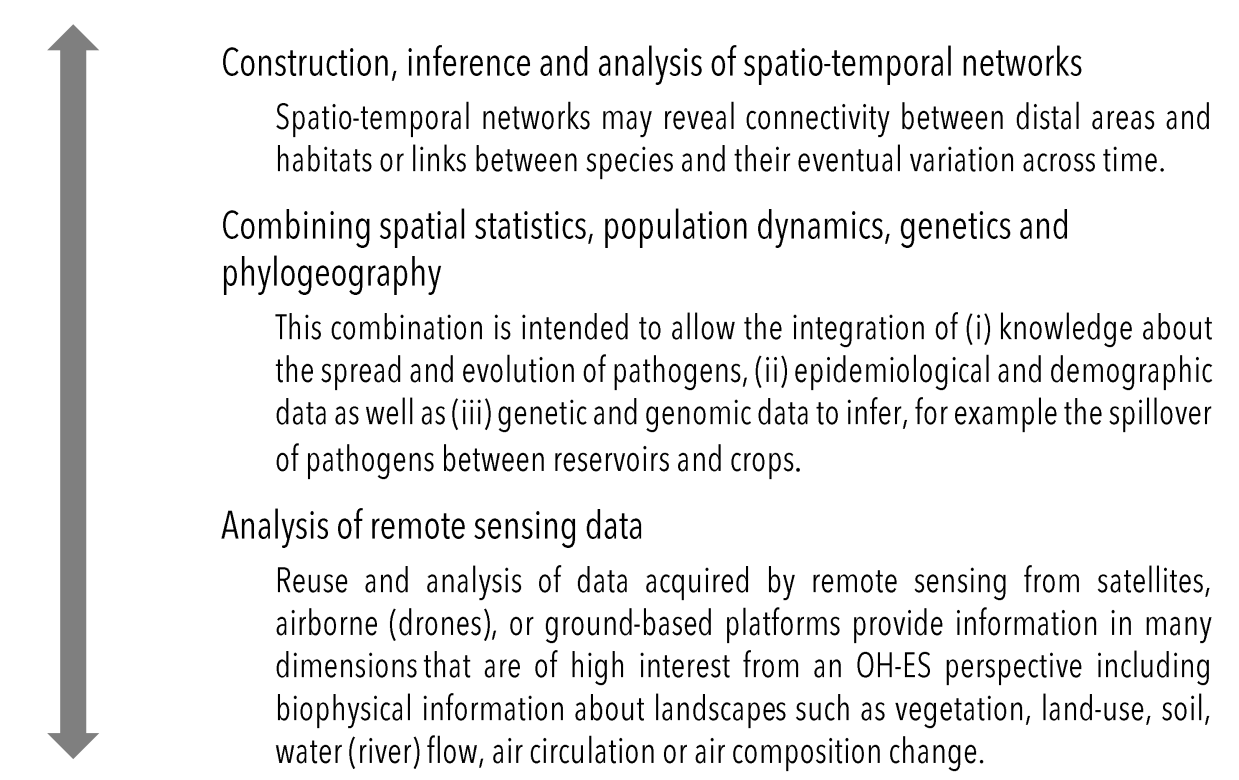

Opportunistic Analysis of data from citizen science and crowdsourcing

data Crowdsourcing of biodiversity observations by private citizens is a powerful method for data collection and interpretation. Examples include plant identification and state of health, or identification of plant-associated insects. The analysis of such data is paramount to amplifying the limited surveillance and observation effort made by governmental and professional agencies.

Multi-actor

approaches

\section{Teaching and capacity building}

The objective is to enhance, in particular, the shift toward the development of One Health vision of plant health at multiple levels of the society, and the ability of researchers and other stakeholders to use large-spectrum data for epidemiological surveillance.

\section{Co-modelling}

The modelling of complex pathosystems in a rich data context can be considerably improved by co-modelling techniques (companion modelling, group model building, mediated modelling) bringing together scientific and technical experts from different disciplines with system stakeholders (consumers, producers, citizens, or policy regulators). These methods are mainly expected to improve the sharing and integration of multidisciplinary knowledge through a joint modelling effort and to produce data and knowledge on the behaviors, perceptions and reactions of stakeholders in different, even hypothetical, contexts. They contribute to a better understanding of certain drivers of pathogen diffusion related to food consumption, agricultural production and environmental management, as well as the existing levers and lock-in for epidemiological surveillance and prevention policy. 


\section{Literature cited}

Abbot A, 2016. Olive tree gridlock eases: court ruling paves way for containment of deadly plant disease, but risk of spread remains. Nature 533, 299-301.

Allen C, Mehler DMA, 2019. Open science challenges, benefits and tips in early career and beyond. PLOS Biology 17, e3000246.

Ashburner M, Ball CA, Blake JA et al., 2000. Gene Ontology: tool for the unification of biology. Nature Genetics 25, 25-29.

Austin KF, 2021. Degradation and disease: Ecologically unequal exchanges cultivate emerging pandemics. World Development 137, 105163.

Barboza P, Vaillant L, Mawudeku A et al., 2013. Evaluation of epidemic intelligence systems integrated in the early alerting and reporting project for the detection of A/H5N1 influenza events. PLOS ONE 8 , e57252.

Bardin M, Leyronas C, Troulet C, Morris CE, 2018. Striking similarities between Botrytis cinerea from nonagricultural and from agricultural habitats. Frontiers in Plant Science 9, 1820.

Bartoli C, Lamichhane JR, Berge 0 et al., 2015. A framework to gauge the epidemic potential of plant pathogens in environmental reservoirs: the example of kiwifruit canker. Molecular Plant Pathology 16, 137-149.

Bordier M, Delavenne C, Nguyen DT, Goutard FL, Hendrikx P, 2019. One health surveillance: A matrix to evaluate multisectoral collaboration. Frontiers in Veterinary Science 6, 109.

Bordier M, Uea-Anuwong T, Binot A, Hendrikx P, Goutard FL, 2020. Characteristics of One Health surveillance systems: A systematic literature review. Preventive Veterinary Medicine 181, 104560.

Bossy R, Golik W, Ratkovic Z, Valsamou D, Bessières P, Nédellec C, 2015. Overview of the gene regulation network and the bacteria biotope tasks in BioNLP'13 shared task. BMC Bioinformatics 16, S1.

Botella $C$, Joly A, Bonnet $P$, Monestiez $P$, Munoz F, 2018. Species distribution modelling based on the automated identification of citizen observations. Applications in Plant Sciences 6, e1029.

Brown JKM, Hovmøller MS, 2002. Aerial dispersal of pathogens on the global and continental scales and its impact on plant disease. Science 297, 537-541.

van Bruggen AHC, Goss EM, Havelaar A, van Diepeningen AD, Finckh MR, Morris JG, 2019. One Health Cycling of diverse microbial communities as a connecting force for soil, plant, animal, human and ecosystem health. Science of the Total Environment 664, 927-937.

Burdon JJ, Thrall PH, 2008. Pathogen evolution across the agro-ecological interface: implications for disease management. Evolutionary Applications 1, 57-65.

de Carvalho MÂAP, Bebeli PJ, da Silva AMB, Bettencourt E, Slaski JJ, Dias S, 2016. Agrobiodiversity: The importance of inventories in the assessment of crop diversity and its time and spatial changes. In: Ahuja $\mathrm{M}_{1 \prime}$ Jain S, eds. Genetic Diversity and Erosion in Plants. Sustainable Development and Biodiversity, vol. 8. Springer Cham., 307-335.

Casadevall A, Pirofski L, 2007. Accidental virulence, cryptic pathogenesis, Martians, lost hosts, and the pathogenicity of environmental microbes. Eukaryotic Cell 6, 2169 LP - 2174.

Center for Disease Control, 2017. https://www.cdc.gov/onehealth/basics/zoonotic-diseases.html. (Accessed 9 March 2019). 
Chaix E, Deléger L, Bossy R, Nédellec C, 2019. Text mining tools for extracting information about microbial biodiversity in food. Food Microbiology 81, 63-75.

Che Z, Purushotham S, Khemani R, Liu Y, 2015. Distilling knowledge from deep networks with applications to healthcare domain. arXiv:1512.03542.

Choufany M, Martinetti D, Senoussi R, Morris CE, Soubeyrand S, 2021a. Spatiotemporal large-scale networks shaped by air mass movements. Frontiers in Applied Mathematics and Statistics, in press, doi: 10.3389/fams.2020.602621.

Choufany M, Martinetti D, Soubeyrand S, Morris CE, 2021b. Long-distance connectivity shaped by air-mass movement: a complex network tool for experimental design in aerobiology. Scientific Reports, IN PRESS.

Cooper WR, Horton DR, Wildung MR et al., 2019. Host and non-host 'whistle stops' for psyllids: Molecular gut content analysis by high-throughput sequencing reveals landscape-level movements of Psylloidea (Hemiptera). Environmental Entomology 48, 554-566.

Cruaud A, Gonzalez A-A, Godefroid M et al., 2018. Using insects to detect, monitor and predict the distribution of Xylella fastidiosa: a case study in Corsica. Scientific Reports 8, 15628.

Daszak P, Cunningham AA, Hyatt AD, 2000. Emerging infectious diseases of wild life - threats to biodiversity and human health. Science 287, $443 \mathrm{LP}-449$.

Daugherty MP, Zeilinger AR, Almeida RPP, 2017. Conflicting effects of climate and vector behavior on the spread of a plant pathogen. Phytobiomes Journa/ 1, 46-53.

Destoumieux-Garzón D, Mavingui P, Boetsch G et al., 2018. The One Health concept: 10 years old and a long road ahead. Frontiers in veterinary science 5, 14.

Dorati F, Barrett G, Sanchez-Contreras M et al., 2018. Coping with environmental eukaryotes; Identification of Pseudomonas syringae genes during the interaction with alternative hosts or predators. Microorganisms 6, 32.

Du M, Liu N, Hu X, 2019. Techniques for interpretable machine learning. Communications of the ACM 63, 68-77.

Duru M, Le Bras C, 2020. Crises environnementales et sanitaires : des maladies de l'anthropocène qui appellent à refonder notre système alimentaire. Cahiers Agriculture 29, 34, https://doi.org/10.1051/cagri/2020033.

Dzale Yeumo E, Alaux M, Arnaud E et al., 2017. Developing data interoperability using standards: A wheat community use case [version 2; peer review: 2 approved]. F1000Research 6, 1843 doi.org/10.12688/f1000research.

Egan F, Barret M, O'Gara F, 2014. The SPI-1-like Type III secretion system: more roles than you think. Frontiers in Plant Science 5, 34.

Erken M, Lutz C, McDougald D, 2013. The rise of pathogens: Predation as a factor driving the evolution of human pathogens in the environment. Microbial Ecology 65, 860-868.

Francis C, Lieblein G, Gliessman S et al., 2003. Agroecology: The ecology of food systems. Journal of Sustainable Agriculture 22, 99-118.

Ghosal S, Blystone D, Singh AK, Ganapathysubramanian B, Singh A, Sarkar S, 2017. Interpretable deep learning applied to plant stress phenotyping. arXiv:1710.08619.

Gliessman SR, 2007. Agroecology: The Ecology of Sustainable Food Systems. New York: CRC Press, Taylor \& 
Francis.

Godefroid M, Cruaud A, Streito J-C, Rasplus J-Y, Rossi J-P, 2018. Climate change and the potential distribution of Xylella fastidiosa in Europe. bioRxiv, https://www.biorxiv.org/content/early/2018/03/28/2.

Goh C-H, Veliz Vallejos DF, Nicotra AB, Mathesius U, 2013. The impact of beneficial plant-associated microbes on plant phenotypic plasticity. Journal of Chemical Ecology 39, 826-839.

Gorter FA, Manhart M, Ackermann M, 2020. Understanding the evolution of interspecies interactions in microbial communities. Philosophical Transactions of the Royal Society B: Biological Sciences 375, 20190256.

Harrison S, Kivuti-Bitok L, Macmillan A, Priest P, 2019. EcoHealth and One Health: A theory-focused review in response to calls for convergence. Environment International 132, 105058.

Häsler B, Cornelsen L, Bennani H, Rushton J, 2014. A review of the metrics for One Health benefits. Revue Scientifique et Technique de l'Office International des Epizooties 33, 453-464.

Helmann TC, Deutschbauer AM, Lindow SE, 2020. Distinctiveness of genes contributing to growth of Pseudomonas syringae in diverse host plant species. PLOS ONE 15, e0239998.

Hinchliffe S, 2015. More than one world, more than one health: Re-configuring interspecies health. Social Science \& Medicine 129, 28-35.

Hohl A, Václavík T, Meentemeyer RK, 2014. Go with the flow: geospatial analytics to quantify hydrologic landscape connectivity for passively dispersed microorganisms. International Journal of Geographical Information Science 28, 1626-1641.

Holman IP, Brown C, Janes V, Sandars D, 2017. Can we be certain about future land use change in Europe? A multi-scenario, integrated-assessment analysis. Agricultural Systems 151, 126-135.

Huang W, Reyes-Caldas P, Mann M et al., 2020. Bacterial vector-borne plant diseases: Unanswered questions and future directions. Molecular Plant 13, 1379-1393.

lenco D, Interdonato R, Gaetano R, Ho Tong Minh D, 2019. Combining Sentinel-1 and Sentinel-2 satellite image time series for land cover mapping via a multi-source deep learning architecture. ISPRS Journal of Photogrammetry and Remote Sensing 158, 11-22.

Isard SA, Gage SH, Comtois P, Russo JM, 2005. Principles of the atmospheric pathway for invasive species applied to soybean rust. BioScience $55,851-861$.

Jonquet $C$, Toulet A, Arnaud E et al., 2018. AgroPortal: A vocabulary and ontology repository for agronomy. Computers and Electronics in Agriculture 144, 126-143.

Khoshbakht K, Hammer K, 2008. How many plant species are cultivated? Genetic Resources and Crop Evolution 55, 925-928.

Lechenet M, Deytieux V, Antichi D et al., 2017. Diversity of methodologies to experiment Integrated Pest Management in arable cropping systems: Analysis and reflections based on a European network. European Journal of Agronomy 83, 86-99.

Malembic-Maher S, Desqué D, Khalil D et al., 2020. When a Palearctic bacterium meets a Nearctic insect vector: Genetic and ecological insights into the emergence of the grapevine Flavescence dorée epidemics in Europe. PLoS Pathogens 16, e1007967.

Marie-Jeanne V, Bonnot F, Thébaud G, Peccoud J, Labonne G, Sauvion N, 2020. Multi-scale spatial genetic structure of the vector-borne pathogen 'Candidatus Phytoplasma prunorum' in orchards and in wild 
habitats. Scientific Reports 10, 5002.

Markel E, Stodghill P, Bao Z, Myers CR, Swingle B, 2016. AlgU controls expression of virulence genes in Pseudomonas syringae pv. tomato DC3000 (A Becker, Ed,). Journal of Bacteriology 198, 2330 LP 2344.

Meyer M, Cox JA, Hitchings MDT et al., 2017. Quantifying airborne dispersal routes of pathogens over continents to safeguard global wheat supply. Nature Plants 3, 780-786.

Mollentze N, Nel LH, Townsend Set al., 2014. A Bayesian approach for inferring the dynamics of partially observed endemic infectious diseases from space-time-genetic data. Proceedings of the Royal Society B: Biological Sciences 281, 20133251.

Monteil CL, Cai R, Liu H et al., 2013. Nonagricultural reservoirs contribute to emergence and evolution of Pseudomonas syringae crop pathogens. The New phytologist 199, 800-11.

Monteil CL, Yahara K, Studholme DJ et al., 2016. Population-genomic insights into emergence, crop adaptation and dissemination of Pseudomonas syringae pathogens. Microbial genomics 2, e000089.

Morris CE, Bardin M, Kinkel LL, Moury B, Nicot PC, Sands DC, 2009. Expanding the paradigms of plant pathogen life history and evolution of parasitic fitness beyond agricultural boundaries. PLoS Pathogens 5(12), e1000693. doi:10.1371/journal.ppat.1000693.

Morris CE, Lamichhane JR, Nikolić I, Stanković S, Moury B, 2019. The overlapping continuum of host range among strains in the Pseudomonas syringae complex. BMC Phytopathology Research 1, 4: https://doi.org/10.1186/s42483-018-0010-6.

Morris CE, Sands DC, Vanneste JL et al., 2010. Inferring the evolutionary history of the plant pathogen Pseudomonas syringae from its biogeography in headwaters of rivers in North America, Europe and New Zealand. mBio 1(3): e001.

Nedellec C, Bossy R, Chaix E, Deleger L, 2018. Text-mining and ontologies: new approaches to knowledge discovery of microbial diversity. 4th International Conference on Microbial Diversity 2017, Oct 2017, Bari, Italy. arXiv arXiv:1805.

Olival KJ, Hosseini PR, Zambrana-Torrelio C, Ross N, Bogich TL, Daszak P, 2017. Host and viral traits predict zoonotic spillover from mammals. Nature 546, 646-650.

Olszak T, Latka A, Roszniowski B, Drulis-Kawa* MAV and Z, 2017. Phage life cycles behind bacterial biodiversity. Current Medicinal Chemistry 24, 3987-4001.

Peterson PD, 2018. The barberry eradication program in Minnesota for stem rust control: A case study. Annual Review of Phytopathology 56, 203-223.

Picard C, Dallot S, Brunker Ket al., 2017. Exploiting genetic information to trace plant virus dispersal in landscapes. Annual Review of Phytopathology 55, 139-160.

Pleydell DRJ, Soubeyrand S, Dallot S et al., 2018. Estimation of the dispersal distances of an aphid-borne virus in a patchy landscape. PLOS Computational Biology 14, e1006085.

Poursat BAJ, van Spanning RJM, de Voogt P, Parsons JR, 2019. Implications of microbial adaptation for the assessment of environmental persistence of chemicals. Critical Reviews in Environmental Science and Technology 49, 2220-2255.

Power AG, Mitchell CE, 2004. Pathogen spillover in disease epidemics. The American Naturalist 164, S79S89.

Przybyła P, Shardlow M, Aubin S et al., 2016. Text mining resources for the life sciences. Database 2016. 
Purahong W, Hoppe B, Kahl Tet al., 2014. Changes within a single land-use category alter microbial diversity and community structure: Molecular evidence from wood-inhabiting fungi in forest ecosystems. Journal of Environmental Management 139, 109-119.

Rakotomalala M, Vrancken B, Pinel-Galzi A et al., 2019. Comparing patterns and scales of plant virus phylogeography: Rice yellow mottle virus in Madagascar and in continental Africa. Virus Evolution 5.

Sicard A, Zeilinger AR, Vanhove M et al., 2018. Xylella fastidiosa: Insights into an emerging plant pathogen. Annual Review of Phytopathology 56, 181-202.

Sletten A, Talgø V, Rafoss T, Melbøe NS, 2017. Fire blight in Norway: A review of strategies and control measures from 1986 to 2016. Journal of Plant Pathology 99, 137-139.

Soubeyrand S, Demongeot J, Roques L, 2020a. Towards unified and real-time analyses of outbreaks at country-level during pandemics. One Health 11, https://doi.org/10.1016/j.onehlt.2020.100187.

Soubeyrand S, de Jerphanion P, Martin 0 et al., 2018. Inferring pathogen dynamics from temporal count data: the emergence of Xylella fastidiosa in France is probably not recent. New Phytologist 219, 824836.

Soubeyrand S, Laine A-L., Hanski I, Penttinen A, 2009. Spatiotemporal structure of host-pathogen interactions in a metapopulation. The American Naturalist 174, 308-320.

Soubeyrand S, Ribaud M, Baudrot V, Allard D, Pommeret D, Roques L, 2020b. COVID-19 mortality dynamics: The future modelled as a (mixture of) past(s). PLOS ONE 15, e0238410.

Steffen W, Leinfelder R, Zalasiewicz J et al., 2016. Stratigraphic and Earth System approaches to defining the Anthropocene. Earth's Future 4, 324-345.

Stokstad E, 2015. Italy's olives under siege: Blight alarms officials across Europe. Science 348, 620.

Thébaud G, Yvon M, Alary R, Sauvion N, Labonne G, 2009. Efficient transmission of "Candidatus Phytoplasma prunorum" is delayed by eight months due to a long latency in its host-alternating vector. Phytopathology 99, 265-273.

Wilkinson MD, Dumontier M, Aalbersberg ljJ et al., 2016. The FAIR guiding principles for scientific data management and stewardship. Scientific Data 3, 160018.

Xue C, 2012. Cryptococcus and beyond-Inositol utilization and its implications for the emergence of fungal virulence. PLOS Pathogens 8, e1002869.

Ye Z-W, Yuan S, Yuen K-S, Fung S-Y, Chan C-P, Jin D-Y, 2020. Zoonotic origins of human coronaviruses. International Journal of Biological Sciences 16, 1686-1697.

Zahn G, Wagai R, Yonemura S, 2016. The effects of amoebal bacterivory on carbon and nitrogen dynamics depend on temperature and soil structure interactions. Soil Biology and Biochemistry 94, 133-137.

Zeglen S, Pronos J, Merler H, 2010. Silvicultural management of white pines in western North America. Forest Pathology 40, 347-368. 